\title{
The effect of plastic waste and elemental sulfur additives on chemical and physical properties of bitumen
}

\author{
M. Ashjari, S. Masoud Kandomal ${ }^{*}$ \\ Chemical Engineering Department, Faculty of Engineering, University of Kashan, P.O. Box 87317-51167, Kashan, \\ Islamic Republic of Iran
}

Received April 22, 2018; Revised March 8, 2019

\begin{abstract}
In this study we describe the modification of bitumen for obtaining better chemical and physical properties. For this goal, we added sulfur or plastic waste in different percentages to the bitumen matrix. The effect of sulfur ratio in the range of $20-40 \%(\mathrm{w} / \mathrm{w})$ and plastic waste ratio in the range of $2-5 \%(\mathrm{w} / \mathrm{w})$ was investigated on the softening point, penetration, tensile factor and loss of weight of bitumen. The obtained data confirmed the improvement in chemical and physical properties of bitumen in the presence of plastic waste and sulfur additives. The results showed that tensile factor of bitumen decreases from $1020 \mathrm{~mm}$ to $820 \mathrm{~mm}$ and $980 \mathrm{~mm}$ after addition of $30 \%$ of sulfur and $3 \%$ of plastic waste, respectively. On the other hand, the best penetration was obtained in the presence of $30 \%$ sulfur and $3 \%$ plastic waste, respectively. Finally, we suggest the application of sulfur and plastic waste as two important additives for bitumen modification.
\end{abstract}

Keywords: Bitumen, Sulfur, Plastic waste, Chemical and physical properties

\section{INTRODUCTION}

Removal of plastic waste is a major and important subject in developed and developing countries. The high volume of plastic waste is now one of the most important environmental problems due to the lack of recovery [1-5]. Therefore, suggesting a new application for this type of materials can be useful for improving quality of life.

Sulfur is a useful and important additive in asphalt mixtures with good properties [6]. Some of the studies showed that sulfur can improve the stiffness of compacted asphalt mixtures [7]. On the other hand, sulfur is a harmful and toxic element obtained from natural gas resources and petroleum. So, application of surplus generated sulfur in a new field can be helpful to environmental health.

Bitumen used for paving (85\%), roofing (10\%) and other uses (5\%) is a black or dark-colored, amorphous, cementitious material that can be found in different forms. New additives can improve the quality and durability of bitumen [8].

In this research, we tried to investigate the effect of elemental sulfur and plastic waste on the chemical and physical properties of bitumen. The study will follow two general purposes, 1) improving the quality of bitumen for application in roads and 2) suggesting a new way for consumption of sulfur and waste plastics as major environmental pollutants. Our results showed that sulfur and waste plastics can improve the chemical and physical

\footnotetext{
* To whom all correspondence should be sent:

E-mail: masoudkandomal@gmail.com
}

properties of bitumen and the optimum conditions for preparation of modified bitumen are described in this work.

\section{EXPERIMENTAL}

\section{Materials}

Bitumen of 60/70 penetration grade was chosen as unmodified bitumen for all investigations. Elemental sulfur with purity of $99 \%$ was used in all experiments. All of the other compounds were purchased from Sigma-Aldrich Company.

\section{Methods}

Process for addition of plastic waste: $500 \mathrm{~g}$ of bitumen 60/70 was put in a metal container and heated at $190{ }^{\circ} \mathrm{C}$ for $30 \mathrm{~min}$. After melting of bitumen, the obtained sample was homogenized with a stirrer for $10 \mathrm{~min}$. Then we added the plastic waste at different ratios $(1 \% ; 2 \% ; 3 \% ; 4 \%$ and $5 \%$ $\mathrm{w} / \mathrm{w})$ and the speed of stirring was increased to 850 rpm for $20 \mathrm{~min}$.

Process for addition of elemental sulfur: $500 \mathrm{~g}$ of bitumen 60/70 was put in a metal container and heated at $190{ }^{\circ} \mathrm{C}$ for $30 \mathrm{~min}$. After melting of bitumen, the obtained sample was homogenized with a stirrer for $10 \mathrm{~min}$. Then, we added the elemental sulfur at different ratios $(0 \% ; 20 \%$; $25.0 \% ; 30 \%$ and $40 \% \mathrm{w} / \mathrm{w})$ and the speed of stirring was increased to $850 \mathrm{rpm}$ for $20 \mathrm{~min}$.

Softening point determination: For determination of softening point we used the standard test ASTM D36 for unmodified and modified bitumen. 
M. Ashjari, S. Masoud Kandomal: The effect of plastic waste and elemental sulfur additives on chemical and physical...

Loss of weight test: For investigation of the loss of weight for bitumen, we used the standard test ASTM D6 and the results of this test were reported according to the weight ratio for total samples with the equation below:

$$
\text { Loss of weight }=\left(\mathrm{W}_{\mathrm{a}}-\mathrm{W}_{\mathrm{b}} / \mathrm{W}_{\mathrm{a}}\right) \times 100
$$

where, $\mathrm{W}_{\mathrm{a}}$ is the weight of sample before input of sample in an air furnace and $\mathrm{W}_{\mathrm{b}}$ is the weight of sample after leaving the furnace.

Tensile test: For study of tensile factor we used the standard test ASTM D113 for unmodified and modified bitumen.

Penetration test: For study of penetration we used the standard test ASTM D5 for unmodified and modified bitumen.

\section{RESULTS AND DISCUSSION}

\section{The effect of plastic waste and elemental sulfur on softening point}

As we know, the softening point is a very important factor for bitumen. The softening point for unmodified bitumen is $\sim 49{ }^{\circ} \mathrm{C}$.

Figures 1 and 2 show the changes in softening point of bitumen after addition of plastic waste and elemental sulfur, respectively.

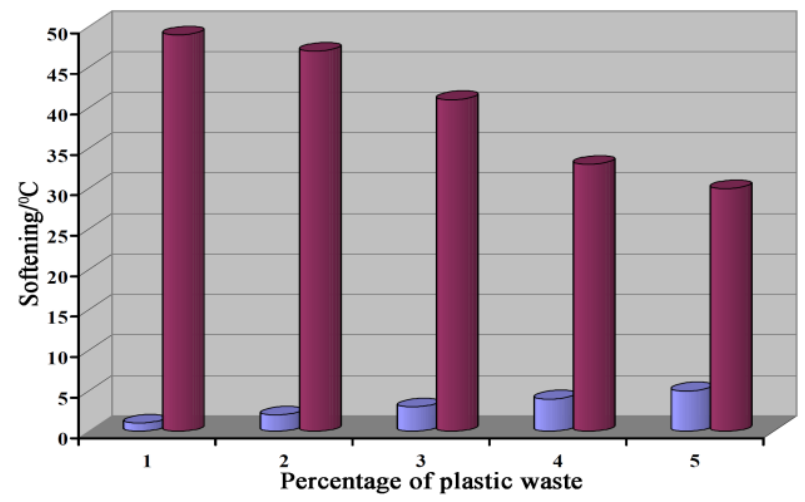

Figure 1. Softening point diagram of bitumen after addition of plastic waste.

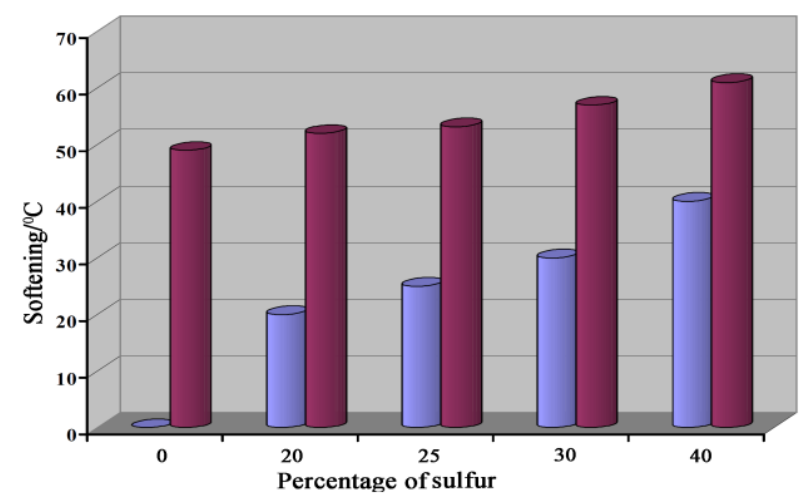

Figure 2. Softening point diagram of bitumen after addition of sulfur.

The obtained results confirmed that the conversion of unmodified bitumen to bitumen modified with $3 \%$ of plastic waste improves the quality of bitumen, but after modification we found a high degree of softening of bitumen that is not a good condition for application of bitumen in industrial materials. The same results were observed after addition of elemental sulfur to bitumen. According to figure 2, we found the best modification of bitumen in the presence of 25-30\% of elemental sulfur.

\section{The effect of plastic waste and elemental sulfur on loss of weight}

For investigation of the effect of plastic waste and elemental sulfur on the loss of weight, we checked the weight of bitumen in the presence of different percentages of plastic waste or elemental sulfur before and after input of bitumen in the furnace. As we know, the best condition is when the weight of bitumen is the same before and after input in furnace.

The same weight of bitumen before and after input of bitumen in the furnace confirmed the stability of additives in the modified bitumen. Tables 1 and 2 show the obtained results for the weight loss of bitumen after addition of plastic waste and elemental sulfur, respectively. The best conditions were obtained in the presence of $3 \%$ of plastic waste and $25-30 \%$ of elemental sulfur.

Table 1. The obtained data for addition of plastic waste on the loss of weight of bitumen

\begin{tabular}{|c|c|c|}
\hline $\begin{array}{c}\text { Percentage of } \\
\text { waste plastic } \\
\text { (w/w) }\end{array}$ & $\begin{array}{c}\text { Weight (g) of } \\
\text { bitumen } \\
\text { before furnace }\end{array}$ & $\begin{array}{c}\text { Weight (g) of } \\
\text { bitumen after } \\
\text { furnace }\end{array}$ \\
\hline 1 & 70 & $68.7 \pm 0.4$ \\
\hline 2 & 70 & $66.3 \pm 0.5$ \\
\hline 3 & 70 & $69.2 \pm 0.7$ \\
\hline 4 & 70 & $68.0 \pm 0.4$ \\
\hline
\end{tabular}

Table 2. The obtained data for addition of sulfur on the loss of weight of bitumen

\begin{tabular}{|c|c|c|}
\hline $\begin{array}{c}\text { Percentage } \\
\text { of sulfur } \\
(\mathrm{w} / \mathrm{w})\end{array}$ & $\begin{array}{c}\text { Weight (g) of } \\
\text { bitumen } \\
\text { before furnace }\end{array}$ & $\begin{array}{c}\text { Weight (g) of } \\
\text { bitumen after } \\
\text { furnace }\end{array}$ \\
\hline 10 & 70 & $66.4 \pm 0.6$ \\
\hline 20 & 70 & $67.2 \pm 0.5$ \\
\hline 30 & 70 & $68.1 \pm 0.3$ \\
\hline 40 & 70 & $69.4 \pm 0.6$ \\
\hline
\end{tabular}

Tensile factor investigation

The tensile factor of bitumen after addition of plastic waste and of elemental sulfur is presented in 
M. Ashjari, S. Masoud Kandomal: The effect of plastic waste and elemental sulfur additives on chemical and physical... figures 3 and 4 . As can be seen the value of tensile factor in the presence of $3 \%$ of plastic waste and $25-30 \%$ of elemental sulfur showed the best stability and good responses.

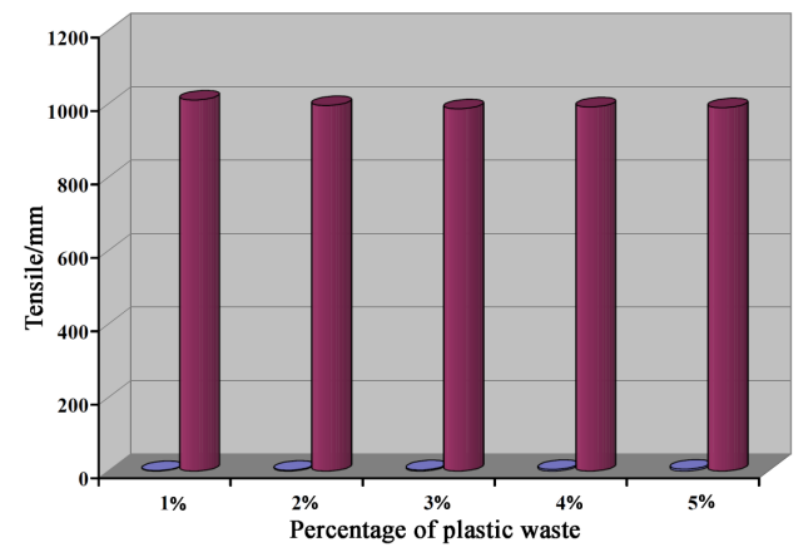

Figure 3. Tensile diagram of bitumen after addition of plastic waste.

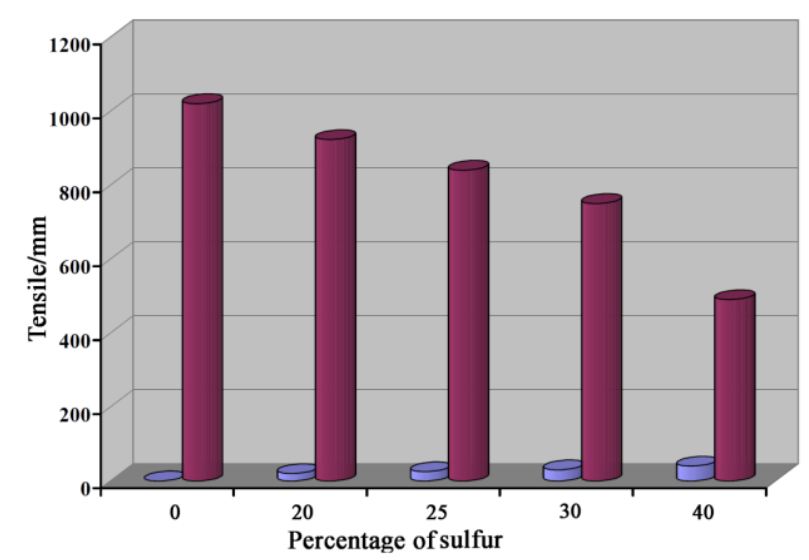

Figure 4. Tensile diagram of bitumen after addition of sulfur.

\section{Penetration investigation}

In the final step, we investigated the effect of the two additives on the penetration properties of bitumen. As we know, the addition of additives can reduce the penetration of bitumen due to binding of sulfur with bitumen functional groups. According to figures 5 and 6 we found the best penetration properties in the presence of $3 \%$ of plastic waste and $25-30 \%$ of elemental sulfur.

\section{CONCLUSION}

In this paper we describe a new strategy for application of two important environmental pollutants in industrial products. As we know, plastic waste and elemental sulfur are two major non-recyclable compounds. The present study describes the application of plastic waste and elemental sulfur for improving the quality of bitumen. We optimized the values of the two additives in the bitumen matrix and we found that 314 bitumen showed the best properties compared to unmodified bitumen in the presence of $3 \% \mathrm{w} / \mathrm{w}$ of plastic waste and $25-30 \%$ w/w of elemental sulfur.

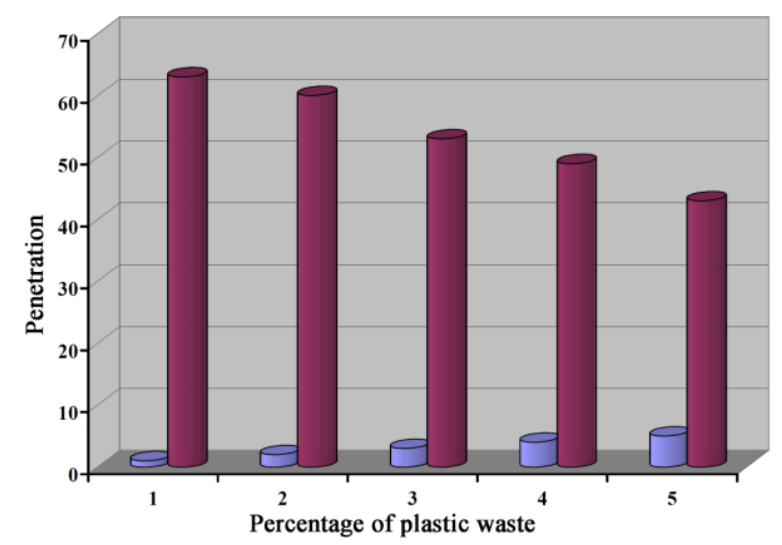

Figure 5. Penetration diagram of bitumen after addition of plastic waste.

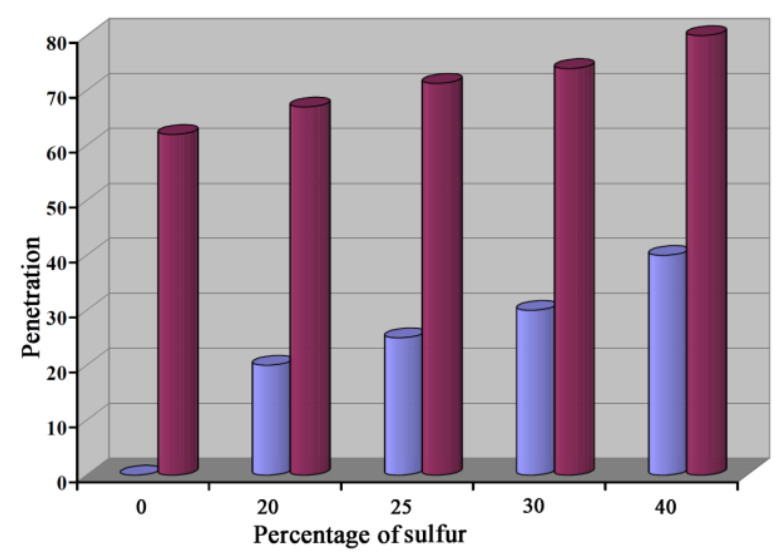

Figure 6. Penetration diagram of bitumen after addition of sulfur.

\section{REFERENCES}

1. J.R. Jambeck, R. Geyer, C. Wilcox, T.R. Siegler, M. Perryman, A. Andrady, R. Narayan, K. Lavender Law, Science, 347, 768 (2015).

2. C.M. Rochman, M.A. Browne, B.S. Halpern, B.T. Hentschel, E. Hoh, H.K. Karapanagioti, L.M. RiosMendoza, H. Takada, S. The, R.C. Thompson, Nature, 494, 169 (2013).

3. Y. Zheng, E.K. Yanful, A.S. Bassi, Critical Reviews in Biotechnology, 25, 243 (2005).

4. E.A. Williams, P.T. Williams, J. Analytical Appl. Pyrolysis, 40-41, 347 (1997).

5. N. Miskolczi, L. Bartha, G. Deák, B. Jóver, Polymer Degrad. Stability, 86, 357 (2004).

6. D. D'Melo, S. Raju, S. Bhattacharya, S. Subramani, Construction and Building Materials, 126, 976 (2016).

7. W.C. McBee, P.A. Romans, T.A. Sullivan, R.R. Uhde, Role of sulfur in SEA pavements, Sulphur Res. Dev., 4, 5 (1981).

8. J. Colange, D. Strickland, G. McCabe, K. Gilbert, R. May, S. Banbury, Road Mater. Pavement, 11, 459 (2010). 